\title{
REVIEW
}

Radiocarbon Dating: An Archaeological Perspective; by R E Taylor. Orlando, Florida, 1987. Academic Press, Inc, 212 pages, $\$ 39.50$.

This is the complete guide to radiocarbon dating, written by the head of a prominent laboratory, for archaeologists and others who need a succinct introduction to the field. Taylor concentrates upon the issues underlying the dating method and discusses them historically so that we learn how the theories and methods developed, as well as the current state of the field. Taylor makes abundant use of examples from archaeology, particularly instances in which radiocarbon results have not accorded with expectations; and he gives reasons why.

The six chapters begin with a discussion of the principles of radiocarbon dating, basic conventions and definitions. Next he describes anomalies that may occur as a result of secular variation, differences in reservoirs, contamination and fractionation, and finally, the effects of the use of fossil fuels and atomic testing. Chapter 3 deals with the collecting of samples and the pretreatments that are or may be carried out in the laboratory. In Chapter 4, Taylor discusses how ages are actually measured through various methods of counting. His final technical chapter concerns the evaluation of radiocarbon data and stresses the role of the archaeologist in securing and adequately documenting samples. The concluding chapter is a brief history of radiocarbon dating, ending abruptly with 1960 when Willard Libby was awarded the Nobel Prize for his role in developing the method. The earlier part of the book, in effect, brings the historical narrative up to date.

The archaeologist will find here information, in a clear and concise form, on any topic, technical or interpretative, that one might raise. The wealth of examples, many bolstered by tables or figures, will be helpful to an instructor in explaining radiocarbon dating to introductory students, and they can also be used to stimulate advanced students to re-examine some of the literature with an eye toward elucidating the reasons behind anomalous dates.

Although the subject matter for the most part is technical, Taylor makes it understandable to one without much background in chemistry or physics. He has taken pains to define terms that might be unfamiliar and to italicize technical definitions that are crucial to understanding. There is minimal use of math; instead, most concepts are conveyed verbally or through the use of graphs.

Most archaeologists have questions about radiocarbon dating. This book, and the references in it, give all the answers, from acquiring samples to interpreting results with and without calibration. We learn much about the methods used in different laboratories and their consequences. And we learn the potential of AMS dating which, at the time of writing, was just beginning to have an impact in the archaeological literature.

The book appears to be unusually free of typographical errors but, as in many archaeological reports of radiocarbon dates, the use of $\mathrm{AD}$ for $\mathrm{BC}$ or vice versa has crept in here as well. In a discussion of how to calculate dates, 
on page 138, Taylor neglects to use $\mathrm{BC}$ for dates that have been adjusted to the calendar. These minor errors in an otherwise fine book merely illustrate that Murphy's Law should be added to the list of uncertainties that plague date lists.

Frank Hole

Anthropology Department Yale University

\section{PRELIMINARY STATEMENT ON AN ERROR IN BRITISH MUSEUM RADIOCARBON DATES (BM-1700 to BM-2315)*}

\section{S TITE, S G E BOWMAN, J C AMBERS, and K J MATTHEWS Research Laboratory, British Museum, London}

A systematic error has been identified in radiocarbon measurements run in the British Museum laboratory between approximately mid 1980 and the end of 1984, when all dating was halted for a number of months. The measurements potentially affected have numbers between about BM1700 and BM-2315, and correspond roughly to date lists XV to XIX published in Radiocarbon. The error is systematic, giving dates that are too young by varying amounts: some may have been underestimated by $200-$ 300 years, whilst others may be little affected. BM dates issued during this period should be used with caution. Dates obtained since mid 1985 are not subject to this error as evidenced by repeated radiocarbon measurements of dendrochronologically-dated wood (see for example BM-2432, date list $\mathrm{XX}$, forthcoming).

A comprehensive set of experiments to clarify and quantify the discrepancy is continuing. When sufficient data are available a full account of the problem will be published. Submitters of a series of samples during the period in question will also be notified individually.

\footnotetext{
* Reprinted from Antiquity, 1987, v 61, p 168.
} 